\title{
PRÁTICAS DE LETRAMENTO EM EXPERIÊNCIAS DE GRUPOS DE ESTUDOS SINDICAIS NO ESTADO DE SERGIPE
}

\author{
Sanadia Gama dos Santos ${ }^{1}$
}

\begin{abstract}
Resumo: O Grupo de Estudos sindicais consiste em atividades de formação de base em sindicatos de trabalhadores e trabalhadoras rurais existentes no Estado de Sergipe, oriundas da Escola Nacional de Formação da CONTAG (Confederação Nacional dos Trabalhadores na Agricultura). O artigo objetiva descrever as práticas pedagógicas desenvolvidas nos Grupos de Estudos Sindicais em sindicatos do Estado de Sergipe e perceber como o letramento social acontece nesse processo, a partir do conceito, em Street (2014), de letramento ideológico, por meio das vivências pedagógico-populares. A metodologia é de natureza qualitativa, e foram utilizados elementos oriundos da etnografia, tais como observação participante e gravações de áudio para o registro das falas dos participantes. O recorte teórico aborda os letramentos sociais propostos por Street (2014), que define o conceito de letramento ideológico como parte integrante da cultura, e por Freire (1996), que valoriza as práticas imersas no contexto local como elemento político, interdisciplinar e identitário. O resultado deste trabalho reafirma a necessidade de a natureza dos letramentos se tornar importante como elementos socioculturais e intimamente associados a valores e identidades presentes em diferentes práticas e dimensões educativas.
\end{abstract}

Palavras-Chave: Letramento. Grupos de Estudos Sindicais. Experiências.

\section{LETTERING PRACTICES IN EXPERIENCES OF GROUPS OF UNION STUDIES IN THE STATE OF SERGIPE}

\begin{abstract}
The Union Study Group consists of basic training activities in rural workers' unions in the State of Sergipe, from the National Training School of CONTAG (National Confederation of Agricultural Workers). The article aims to describe the pedagogical practices developed in the Union Study Groups in unions in the State of Sergipe and also understand how social literacy happens in this process, based on the concept in, Street (2014), of ideological literacy through pedagogical-popular experiences. The methodology is by qualitative nature and elements from ethnography were used such as participant observation and audio recordings which the last one was used to record the speeches of the participants. The theoretical approach addresses the social literacies proposed by Street (2014), which defines the concept of ideological literacy as an integral part of culture and by Freire (1996), who values practices
\end{abstract}

\footnotetext{
${ }^{1}$ Doutora em Letras pela Universidade Estadual de Maringá (UEM). Mestra em Letras pela Universidade Federal de Sergipe. Professora da Universidade Estadual de Alagoas (UNEAL). E-mail: sanadiasantos@yahoo.com.br.
} 
immersed in the local context as a political element, interdisciplinary and identity. The result of this work reaffirms the need for the nature of literacies to become important as socio-cultural elements and closely associated with values and identities present in different educational practices and dimensions.

Keywords: Literacy. Union Study Groups. Experiences.

\section{Introdução}

Este artigo apresenta uma reflexão acerca de experiências formativas de Grupos de Estudos Sindicais - doravante GES -, que é uma atividade organizada por sindicatos de Trabalhadores e Trabalhadoras Rurais filiados ao Movimento Sindical de Trabalhadores e Trabalhadoras Rurais, que visa ao processo de formação de grupos de estudos sindicais e que consiste em práticas multiplicativas oriundas do itinerário formativo da Escola Nacional de Formação da CONTAG - Confederação Nacional dos Trabalhadores na Agricultura.

A formação dos Grupos de Estudos Sindicais destina-se a trabalhadores e trabalhadoras rurais filiados/as aos sindicatos de trabalhadores e trabalhadoras rurais e é conduzida por educadoras e educadores populares formados/as pela Escola nacional de Formação doravante ENFOC -, que atuam como multiplicadores/as no processo de formação em suas bases locais.

O trabalho é realizado em forma de temáticas específicas que se destinam à conscientização e a uma maior compreensão acerca da história de luta dos trabalhadores e do movimento sindical e possui, em seu desenvolvimento, práticas pedagógicas baseadas nos princípios da sociabilidade e na construção coletiva de saberes e troca de conhecimentos, tendo como alicerce a pedagogia freireana, sendo baseado, com efeito, na açãoreflexão-ação.

Os GES são espaços de estudos, debates, ações e, portanto, formação, que assumem como objetivos: qualificar o "fazer sindical" de dirigentes e funcionários de associações, cooperativas e sindicatos, além de estimular novas lideranças de base; fortalecer o MSTTR - Movimento Sindical de Trabalhadores e Trabalhadoras Rurais - por meio do estímulo à participação militante, à regularização de sócios/as inadimplentes e à sindicalização de 
novos/as sócios/as; aprofundar o conhecimento sobre o papel e a importância do MSTTR, bem como sobre sua história, suas lutas, suas conquistas e seus símbolos; estimular a cultura do estudo e diálogos reflexivos entre dirigentes, lideranças e funcionários de STTRs - Sindicatos de Trabalhadores e Trabalhadoras Rurais -, além da pesquisa sobre os temas político-sindicais em diálogo com as especificidades locais. Acrescente-se a isso estimular e contribuir com a organização de secretarias e coletivos de formação nos Sindicatos de Trabalhadores/as Rurais e nas Federações que ainda não os tenham.

A multiplicação dos GES, para a CONTAG, é uma forma de estar com os pés no chão do campo, semeando fazeres e saberes nas comunidades rurais, sentindo, procurando compreender e expandindo suas frentes de lutas para vencer as contradições que não foi possível serem superadas em toda a sua história. Para a CONTAG, suas Federações e seus Sindicatos, há muito ainda por ser feito para se viabilizar a consolidação do Projeto Alternativo de Desenvolvimento Rural Sustentável e Solidário - PADRSS -, da Política Nacional de Formação - PNF -, e, com isso, promover profundas transformações no campo brasileiro. A reforma agrária, as condições de produção e manutenção na terra, o fortalecimento da agricultura familiar, os direitos à saúde e à educação, a melhoria das condições de trabalho e de vida digna no campo continuam sendo bandeiras de luta que não perderam atualidade neste ano em que a CONTAG celebra seu cinquentenário.

Nesse contexto, o presente artigo trata-se de um recorte de um processo de sistematização escrita de experiências de grupos de estudos sindicais. A partir dele, vamos contar histórias passadas nos municípios que compreendem as regiões Cotinguiba, Centro-Sul, Sul e Sertão do Estado de Sergipe.

Vale ressaltar que a constituição desses grupos se deu desde 2008, durante vivência nos cursos nacionais e no Curso Regional Nordeste da ENFOC, interpelada pela provocação das atividades intermódulos, as quais ocorreram durante a realização dos referidos cursos. Enfatizamos a atividade formativa que ocorre no intervalo entre um módulo e outro do curso, momento esse em que os/as educandos/as assumem compromissos e vivenciam a atividade em sua comunidade local (tempo-comunidade). Isso partiu de um compromisso 
pessoal de indivíduos envolvidos na vivência do Itinerário proposto pela Escola a partir dos cursos. Com a proposta política da ENFOC, os envolvidos e as envolvidas foram desafiados/as e incentivados/as a dar o primeiro passo nas suas bases de origem.

Diante disso, o artigo objetiva descrever as práticas de Grupos de Estudos Sindicais em dois grupos do Estado de Sergipe: São Cristóvão e Cumbe, e perceber como o letramento social acontece nesse processo, a partir do conceito, em Street (2014), de letramento ideológico como um conjunto de práticas sociais, na medida em que as formas pelas quais as pessoas usam a leitura e a escrita estão vinculadas às questões de conhecimento e de identidade e aos modos de ser e estar no mundo, seja nas práticas sociais, seja em contextos específicos. Dessa maneira, os letramentos desses sujeitos estarão dependentes desses contextos, e as relações de poder desempenham um papel predominante nisso. Destacamos, ainda, que Street (2014) considera as práticas de letramento como indissoluvelmente ligadas às estruturas culturais e de poder da sociedade e reconhece a variedade de práticas culturais associadas à leitura e à escrita em diferentes contextos.

\section{Os grupos de estudos sindicais e o desenvolvimento da proposta pedagógica de formação de base}

Segundo Freire (1996), aprendemos bastante no dia a dia, vivendo, trabalhando, no lazer, enfim, fazendo coisas e interagindo com o outro. Aprendemos não somente por meio da educação formal, mas também pela informalidade das vivências e do sistema educativo altamente institucionalizado, que se estende do Ensino Fundamental à Universidade, e por meio da Educação não formal.

A Educação não formal tem também contribuído para a transmissão do conhecimento que, ao longo do tempo, as sociedades vêm acumulando. Assim, este texto pretende revelar o que está presente na poeira das estradas interior afora do Estado de Sergipe, através das manifestações de anseios e desejos de um povo que sabe fazer desse presente a produção de um viver. Nesse sentido, salientamos que as atividades dos Grupos de Estudos Sindicais desenvolvem vários tipos de aprendizagens, por meio de diversas linguagens e 
recursos utilizados na Educação Popular. Sendo assim, compreendemos o letramento como um fenômeno social (LOPES, 2004; STREET, 2014), ou seja, as práticas locais situadas em torno das atividades desenvolvidas em espaços não escolares, são determinadas por elementos socioculturais que configuram essas práticas no contexto local de grupos sociais.

A descrição dos grupos de base no Estado de Sergipe constitui-se parte da estrutura do Movimento Sindical de Trabalhadores e Trabalhadoras Rurais, a partir da Federação dos Trabalhadores na Agricultura do Estado de Sergipe - FETASE -, organizada por cinco polos sindicais agregados por sindicatos que se aproximam geograficamente por territórios.

Para os intentos deste texto, o nosso foco compreende dois municípios dos cinco polos nos quais se situam as experiências dos GES. São, também, dois municípios - São Cristóvão (Vale do Cotinguiba) e Cumbe (Sertão) - que se tornaram objeto de nossa sistematização.

Com esse caminho percorrido, compreendemos que as quatro experiências apresentadas têm uma motivação em comum no seu jeito de dar o primeiro passo. Elas surgem da dinâmica e dos desdobramentos que aparecem nos cursos em que sujeitos se envolvem e seguem para a base de origem de cada um/a. Agregam sonhos e o desejo de transformação que está refletido em novas formas de pensar a luta sindical, de adquirir maturidade sobre o seu papel enquanto militante e de se relacionar com as pessoas de uma forma mais ampla, garantindo, assim, novas práticas no interior do Movimento Sindical do Estado.

No processo de conhecimento, ao participar do Itinerário formativo da ENFOC, foi surgindo entre esses sujeitos o compromisso de propiciar aos integrantes das suas comunidades de origem - as bases do Movimento - a oportunidade de também fazerem a experiência do diálogo, que favorece a expressão dos seus saberes, o acesso a informações e o desenvolvimento da curiosidade, da capacidade de crítica e da vontade de construção de projetos conjuntos para melhorar as próprias vidas e a da comunidade.

Nesse sentido, Rojo (2006) e Moita Lopes (2007) afirmam que o lugar epistêmico está voltado para problemas com relevância social suficiente para exigirem respostas teóricas que tragam ganhos para práticas sociais, no sentido 
de uma melhor qualidade de vida. Essa filiação implica um posicionamento político e uma concepção de conhecimento que revela preocupação com contribuições para o entorno que contribuam para qualificar a vida humana (MOITA LOPES, 2007).

\section{O Ges nos sindicatos}

A experiência dos GES em São Cristóvão, município que fica situado na região do Vale do Cotinguiba, a $26 \mathrm{~km}$ da capital, Aracaju, é a primeira a ser situada aqui. São Cristóvão é a quarta cidade mais antiga do Brasil e foi a primeira capital de Sergipe. Fundada por Cristóvão de Barros, no dia 1 e janeiro de 1590, é marcada como patrimônio histórico da humanidade. Embora tenha recebido esse título, por seu rico acervo cultural e pelos monumentos e aspectos históricos, caracteriza-se por áreas de cultivo da cana, pela agricultura e pela pesca do camarão.

No município, existe um Sindicato dos Trabalhadores e Trabalhadoras Rurais e, também, estão constituídos dois GES, um que envolve grupos que trabalham com a criação de camarão - aquicultores/as rurais - e outro que é eminentemente de trabalhadores e trabalhadoras rurais, sócios/as do sindicato.

Por sua vez, o município de Cumbe está situado na região do Médio Sertão Sergipano e possui cerca de 3.144 habitantes. O município vive predominantemente da agricultura familiar, da pecuária e do serviço público local. O grupo de estudos foi criado neste município em julho de 2011, com a participação da presidente do STTR, durante o Curso Regional Nordeste da ENFOC. A partir da atividade intermódulo, Marlene sentiu-se no compromisso de iniciar um novo grupo no seu município, em conformidade com a estratégia que a ENFOC propunha. No início, o GES de Cumbe continha 11 integrantes. O primeiro grupo, criado em 2011, é composto por nove pessoas, e o segundo, formado em 2012, por seis membros, coordenados por duas educadoras da quarta turma do Curso Estadual ENFOC/SE. 


\section{O letramento como prática social no desenvolvimento das atividades educativas no ges}

Nesta seção apresentaremos o desenvolvimento das atividades dos grupos de estudos sindicais ocorridas nos municípios. Para isso adotaremos como base epistêmica de análise a teoria dos Novos Estudos do Letramento. Nesse sentido, o letramento é visto como um conceito vinculado às práticas sociais. Tais práticas se associam a um modelo circular e horizontal de saberes e que estão moldadas no chão das experiências, utilizando-se como base de formação temas que são aprofundados na vida sindical e suas lutas e histórias.

Desse modo, o Letramento como prática social trata-se de uma abordagem sociocultural que está em todo o projeto teórico-metodológico dos Estudos do Letramento, pois reconhece e busca a diversidade nas práticas de letramento, tomando como relevante o modo como as pessoas agem e interagem como interlocutoras e sobre objetos (textos, discursos, suportes materiais), orientando-se por modos culturais, "como agem, constroem, assumem, transformam ou preservam suas identidades sociais" (SILVA; ASSIS; BARTLETT, 2013, p. 12). É com base nas práticas sociais, por meio dos depoimentos apresentados que, segundo Guber (2005) o trabalho de campo não fornece dados, mas informações que elaboramos como dados. As informações se transformam em dados no processo reflexivo, posteriormente à sua coleta

Nesse campo de estudos, o letramento está associado às questões de identidade em construção. Articulamos, portanto, possibilidades de compreensão do conceito de identidade trazidas pelas teorias pós-modernas, discutindo que identidade é algo em construção, dinâmico e heterogêneo (HALL, 2000).

\section{O desenvolvimento das atividades}

A metodologia de trabalho se desenvolve em círculo. Existe um baú que foi feito pela animadora do GES desde a primeira reunião. Antes de iniciar a reunião, todos os materiais didáticos são colocados nesse baú, como bandeiras de tecidos. No início, o assunto a ser abordado não é trazido de imediato. Há sempre uma dinâmica de sensibilização para o grupo entrar no 
clima. Essa dinâmica pode ser de integração, contendo músicas, mensagens ou até reflexões feitas pela facilitadora.

Os temas abordados são: história do STTR, Projeto Alternativo de Desenvolvimento Rural Sustentável e Solidário, preservação do meio ambiente, organização das mulheres, estatuto do sindicato, política partidária, entre outros. Os depoimentos das pessoas mais velhas dão-se pela presença ativa delas durante as reuniões, principalmente quando a temática central da discussão é a história do STTR. Neste momento, é convidado/a algum fundador ou alguma pessoa que participou do processo de sua fundação, e este/a vem relatar, mediante depoimento, as experiências vividas ao longo desse período.

A ciranda pedagógica é o recurso pedagógico mais frequente nos grupos. Esse tipo de ciranda se dá no formato da horizontalidade, desde a organização das cadeiras em círculo, conforme metodologia da Educação Popular, como também por intermédio das canções que são trazidas nas reuniões, na forma democrática de as pessoas terem a liberdade de expressão para intervirem no debate, tornando os envolvidos uma parte integrante dessa construção. Essa forma acaba horizontalizando o jeito de conduzir os processos e favorece a participação dos/as envolvidos/as nas ações que se relacionam com os temas e suscitam no povo novas formas de enxergar o mundo e a vida, fortalecendo, com isso, seu agir cotidiano, (re)significando sua atuação e os transportando a novas práticas.

Essa relação de saberes e linguagens, as identidades são, portanto, constructos sociais e não propriedades dos indivíduos de modo essencialista e fixo. A construção dos sujeitos se estabelece na posição perante o outro em um jogo de forças e nas relações de poder. De acordo com Moita Lopes (2003), estamos imersos em um universo multicultural que atravessa os limites nacionais, em que as mudanças culturais, sociais e culturais se refletem no cotidiano de comunidades locais específicas. Sendo assim, os grupos de estudos sindicais vêm desenvolvendo metodologias a partir de músicas, uso de tarjetas, linguagens corporais que se relacionam com as temáticas trabalhadas nos encontros de estudos e agindo de forma pedagógica na ação concreta dos/as envolvidos/as no processo. O trecho do relato a seguir é exemplificativo dessa conjuntura: 
Através dessas discussões nos GES, melhorei a forma de ver e de pensar o Movimento sindical e sua luta com mais empoderamento e conhecimento para a minha militância (Socorro - Educadora da ENFOC, Presidenta do STTR de São Cristóvão).

Era o ano de 2010, período em que Socorro realizava o Curso Regional Nordeste da ENFOC. Com isso, as reuniões do grupo se tornaram regulares, conforme depoimento de um dos integrantes: "Essas reuniões ajudam a ter informações do que se passa no cenário em nível de estado. Isso ajuda a manter o nosso grupo fortalecido" (Marcos, aquicultor). As reuniões são feitas no próprio viveiro, popularmente conhecido como tanque. Durante essas ocasiões, é feita a abertura do momento formativo, e o tema é escolhido pelas lideranças. Trata-se de um grupo formado por 15 participantes, e também se reúnem alguns alunos da Universidade Federal de Sergipe, que fazem parte de alguns temas tratados no grupo de pesquisa. Há uma parceria com o GEAS Grupo de Pesquisas da Universidade Federal de Sergipe -, que contribui com o grupo no acompanhamento do processo de criação dos camarões e de espécies nativas, de maneira que possa fortalecer sua produtividade.

Dessa maneira, a colaboração, como afirmam Kersch e Silva (2012), o espírito colaborativo, a parceria com a Universidade, as práticas formativas em torno do viveiro, as reuniões que tocam em diversos temas relacionados ao trabalho com a criação de camarão constituem essa prática de letramento.

Além disso, são discutidos temas diversos, como gênero, por intermédio do caderno da Marcha das Margaridas, folheando-se os textos de forma coletiva, com perguntas norteadoras e respostas que são realizadas e debatidas de modo participativo. A experiência é feita numa relação dialógica entre teoria e prática, quando se discutem temas, a exemplo de meio ambiente, história do movimento sindical, habitação rural e crédito fundiário, entre outros. Um dos temas mais debatidos é o da preservação ambiental - as pessoas ouvem, olham ao redor da sua realidade, e, com isso, o grupo tem realizado ações que causam menor impacto para a natureza. Nesse contexto, pessoas que viviam na maré pescando ou só na agricultura, hoje, além de serem agricultoras, também são aquicultoras.

Em outro momento do relato, destaca-se que: 
Com a vinda do GES, renovamos as forças e outras pessoas também estão criando viveiros desta forma mais sustentável com este trabalho (Socorro, Educadora popular e coordenadora do grupo de estudos sindicais de São Cristóvão).

Logo, consideramos que esse fazer diferente contribui para a autoorganização, para o esclarecimento e para a politização dos/as aquicultores/as. Isso porque, normalmente, não temos o hábito de ser politizados. Consequentemente, renovam-se as forças e se cria a possibilidade de práticas mais sustentáveis de trabalho.

É possível dizer que esses momentos de reuniões dos GES na associação melhoraram a qualidade de vida dos/as envolvidos/as. Antes eles/as pescavam como antigamente, de forma artesanal, somente com a produção da pesca de peixes nativos de forma isolada. Hoje, eles/as produzem para sua própria subsistência e a de suas famílias. Atualmente, há em média 30 pessoas no cultivo da pesca do camarão e, após a participação na organização, ampliaram suas próprias áreas. Com o agir coletivo, o dinheiro arrecadado é dividido entre eles/as. Isso agrega valor, havendo, ainda, respeito uns com os outros, união e fortalecimento do grupo.

Segundo Street $(1984,2014)$, as práticas situadas estão atualizadas por outras semioses presentes na sociedade que organizam os modos de (inter)agir das pessoas nas suas atividades sociais. Dessa perspectiva, são múltiplas e heterogêneas as práticas letradas. Estudos, como o de Kersch e Silva (2012), descrevem letramentos fora da escola, os quais podem ser colaborativos na instituição, pois, para as autoras, “a colaboração é corrente e a instituição como indivíduo passa pela reconstituição" (KERSCH; SILVA, 2012, p. 395).

Nesse âmbito, a mencionada reconstituição ocorre no dinamismo das diferentes práticas letradas, e esses letramentos fora da escola contribuem para a compreensão de modelos de letramento escolares situadamente, os quais vão além de habilidades neutras de aprendizagem propostas muitas vezes por agências e órgãos de educação. Além disso, Street (2006) traz, em seu artigo "Perspectivas interculturais sobre letramento", a visão a partir do conceito de pessoalidade, dizendo que "a pessoalidade é mais bem vista como um campo 
que é ideologicamente estruturado", uma vez que a pessoa "está em um lugar em que há articulação de componentes ideológicos e subordinados".

\section{Considerações finais}

Este estudo permitiu intercompreensões sobre práticas de letramento em contextos de formação fora do contexto escolar. Nesse sentido, percebemos que a natureza dos letramentos nos grupos de estudos sindicais nos aponta um entendimento de que as práticas sociais são dinâmicas e se constituem como valores significativos no ato educativo, através de uma formação crítica e reflexiva, que desencadeia mudanças significativas na vida dos grupos sociais.

Assim, vemos que as práticas apresentadas neste artigo possuem uma dimensão sociocultural de saberes porque se entrelaçam com a ideia de que as práticas de letramento no GES promovem interação, e, com isso, há movimentos de constituição identitária local que legitimam os saberes e a vida vivida localmente.

O modo de agir entre as relações de trabalho (vida sindical, organização em torno da criação de camarão), permeadas por práticas de estudos, vivências em torno dos cadernos formativos do Movimento Sindical e das habilidades adquiridas no itinerário formativo dos Cursos da Escola de Formação Nacional da CONTAG-ENFOC, contribui na medida em que orienta um propósito comunicativo afetado pelos sentidos e pelas posições identitários. As formas do uso da leitura em torno dos debates com os textos e relacionando com suas lutas e histórias estão associadas a determinadas identidades e expectativas sociais acerca dos modelos de comportamento e papéis que os indivíduos têm a desempenhar.

\section{Referências}

FREIRE, Paulo. Pedagogia da Autonomia: saberes necessários à prática educativa. São Paulo: Paz e Terra. 1996.

GUBER, Rosana. El salvaje metropolitano. Reconstrucción del conocimiento social em el trabajo de campo. Buenos Aires: Paidós, 2005. 
HALL, Stuart. Quem precisa da identidade?. In: SILVA, Tomaz Tadeu (Org. e Trad.). Identidade e diferença: a perspectiva dos estudos culturais. Petrópolis: Vozes, 2000. p. 103-133.

KERSCH, D. F.; SILVA, M. O. Meu modo de falar mudou bastante, as pessoas notaram a diferença em mim: quando o letramento é desenvolvido fora do contexto escolar. Trabalho em Linguística Aplicada, Campinas, v. 51, n. 2, p. 389408, jul./dez. 2012.

LOPES, Iveuta de Abreu. Cenas de Letramentos Sociais. 212f. (Doutorado em Linguística). Universidade Federal de Pernambuco. Recife, 2004.

MOITA LOPES, Luiz Paulo da (Org.). Discursos de identidades: discurso como espaço de construção de gênero, sexualidade, raça, idade e profissão na escola e na família. Campinas, SP: Mercado das Letras, 2003.

MOITA LOPES, L.P. Da aplicação linguística à linguística aplicada indisciplinar. Palestra proferida na UFPB e UFG. No prelo, 2007.

ROJO, R. H. R. Fazer Linguística Aplicada em perspectiva sócio histórica: privação sofrida e leveza de pensamento. In: MOITA-LOPES, L. P. (Org.) Por uma Linguística Aplicada indisciplinar. São Paulo: Parábola, 2006a. pp. 253-276.

SILVA, J. Q. G.; ASSIS, J. A.; BARTLETT, L. Letramento e identidade: Questões em estudo. SCRIPTA, Belo Horizonte, v. 17, n. 32, p. 9-22, 1ㅇ sem. 2013.

STREET, B. Literacy in theory and practice. Cambridge: Cambridge University Press. 1984.

STREET, B. Perspectivas interculturais sobre o letramento. Revista Filologia e Linguística Portuguesa, São Paulo, v. 8. 2006.

STREET, B. Letramentos sociais: abordagens críticas do letramento no desenvolvimento, na etnografia e na educação. São Paulo: Parábola. 2014.

Recebido em 29 de abril de 2020.

Aceito em 20 de junho de 2020. 